\title{
PAISAXES DESDE O MOVEMENTO: ESTRADAS E CAMIÑOS DE FERRO ESCÉNICOS
}

Data recepción: 2012/02/02

Data aceptación: 2012/07/20

Contacto autor: miguel.pazos.oton@usc.es
Miguel Pazos Otón Rubén C. Lois González Valerià Paül Carril

Universidade de Santiago de Compostela

\section{RESUMO}

A sociedade actual caracterízase pola importancia da mobilidade en todos os seus ámbitos. A observación e o gozo da paisaxe danse non só dende unha perspectiva estática, senon tamén dende o movemento. As achegas dende a Xeografía á comprensión deste feito parten dos conceptos de transporte e mobilidade, e inscríbense dentro da Xeografía do Turismo.

No presente artigo realizamos unha achega ao estado da cuestión na actualidade, centrándonos nas estradas e nos camiños de ferro escénicos como elementos fundamentais para apreciar as paisaxes desde o movemento.

Palabras clave: paisaxes, transporte, mobilidade, estradas escénicas, camiños de ferro escénicos

\begin{abstract}
Modern society is characterised by the importance of mobility in all its spheres. Contemplation and enjoyment of the landscape occur not only from a static perspective, but also as a result of movement. Geographical approaches to this are based on the concepts of transport and mobility and are encompassed within the geography of tourism.
\end{abstract}

This article offers an analysis of the current state-of-the-art, and focuses on scenic roads and railways as core elements in appreciating landscapes while in motion.

Keywords: landscapes, transport, mobility, scenic roads, scenic railways

\section{Introdución}

$\mathrm{Na}$ actual sociedade, a accesibilidade e a velocidade son elementos fundamentais (HANDY, 1997; VIRILIO, 1986). O aumento da mobilidade individual en función dos diferentes motivos (traballo, estudo, compras, ocio, saúde, etc) traduciuse nun proceso de compresión espazotemporal notábel (ALLEN e HAMNETT, 1995), onde os modos de transporte desempeñan un papel fundamental. Cada vez desprazámonos con máis frecuencia, por máis e diferentes motivos, percorremos maiores distancias, e facémolo a maior velocidade (PAZOS, 2005).

Estamos nun mundo que semella estar todo el en movemento ("on the move", en expre- sión anglófona) (URRY, 2007: 3). Autores como CRESSWELL recorren tamén sistematicamente a esta expresión para aludir á importancia do movemento na actualidade (CRESSWELL, 2006).

Para URRY, na actualidade estariamos asistindo a un cambio de paradigma nas Ciencias Sociais, denominado "mobility turn", caracterizado pola importancia do movemento constante de persoas, mercadorías, información e capitais para explicar a realidade. Este novo paradigma explicativo supera as visións estáticas do "espazo dos lugares" a favor do "espazo dos fluxos", que deron en denominar as Ciencias Sociais tales como Xeografía, Antropoloxía, Socioloxía, etc. O novo paradigma insiste na idea de mobilizar 
unhas análises que até o momento teñen sido estáticas ou a-espaciais, en campos do coñecemento tales como estudos culturais, migracións, turismo ou outros (URRY, 2007: 6).

Segundo URRY, no cerne deste novo paradigma atópanse os traballos de SIMMEL e BENJAMIN, así como os de DELEUZE e LEFEBVRE. Asemade, foron moi importantes conceptos como a "dromoloxía" de VIRILIO (1997), a "modernidade líquida" de BAUMAN (2000) ou o "movemento-espazo" de THRIFT (2004).

Este novo escenario obriga a repensar moitas das achegas que dende a Xeografía se realizaron sobre conceptos fundamentais como o de paisaxe. Tradicionalmente, un viaxeiro desprazábase entre dous lugares, e tiña tempo de saborear e apreciar as paisaxes. As baixas velocidades e o carácter pouco intrusivo das infraestruturas facíano posíbel. Hoxe en día, circular por autoestradas ou vías de alta velocidade resulta enormemente práctico, pero elimina (ou reduce moitísimo) o pracer estético da contemplación da paisaxe.

A presenza de grandes espazos de servidume nas marxes, a existencia de noiros e de túneles, e a propia velocidade do desprazamento explican que cando viaxamos vexamos fragmentos de paisaxe, ou que non poidamos apreciala no seu conxunto. En moitos casos podemos falar dun "efecto túnel", xa que para moitos viaxeiros o único importante é chegar rápido dende un punto $A$ a un punto $B$, e neste sentido é irrelevante o que acontece no medio do traxecto. Así, tense falado das autoestradas como "túneles transparentes". Este efecto acada o seu apoxeo no caso do transporte aéreo, onde a paisaxe entre a orixe e o destino queda anulada, suprimida, furtada ao viaxeiro, en beneficio da urxencia na viaxe e, cada vez máis (ao contrario do que sucedía antes), dos custos de transporte (GUTIÉRREZ PUEBLA, 1988).

Deste xeito, a necesidade de viaxar o máis rapidamente posíbel, e de facelo co menor custo leva a que moitas persoas deixen de ver paisaxes. Até agora, a viaxe era unha magnífica escusa para ver, apreciar e reencontrarse casual e periodicamente coas paisaxes. Admirar paisaxes era unha vantaxe adicional asociada ao feito de viaxar. Na actualidade, viaxar equivale case sem- pre a chegar coa maior brevidade dende un punto a outro, coa conseguinte perda da experiencia paisaxística.

Ante esta diminución progresiva de contacto do viaxeiro coas paisaxes, existe un movemento de réplica que se basea no concepto da slow mobility ou mobilidade lenta. Asume a importancia da mobilidade e o desprazamento como un xeito de apreciar as paisaxes, pero faino dende a reivindicación dun ollar pausado e sereno, asociado a unha velocidade lenta. Entramos así de cheo no "turismo escénico", unha modalidade onde o turista procura gozar e apreciar a paisaxe, ou en determinados tipos de turismos onde a contemplación e o gozo da paisaxe desempeñan un papel moi importante.

Percorrer un itinerario nun tren turístico, realizar unha ruta de peregrinación como o Camiño de Santiago, seguir un "itinéraire de découverte" ou conducir por unha "scenic road" son experiencias onde movemento e paisaxe están intimamente relacionadas. Nesta análise son útiles e necesarias as achegas da Xeografía do Turismo e o propio estudo interdisciplinario da Paisaxe, que combinaremos neste traballo.

\section{O transporte e a mobilidade no turis- mo: unha achega teórica}

No ámbito da Xeografía, o estudo da mobilidade da poboación aparece encadrado dentro da Xeografía do Transporte. Esta rama da Xeografía acadou identidade propia nos anos posteriores á Segunda Guerra Mundial, cando Ullman, considerado o seu pai fundador, institucionalizouna no seo da Association of American Geographers (AAG).

Durante a maior parte da segunda metade do século $X X$, os estudos xeográficos de transporte realizados en Norteamérica e Europa teñen abordado a cuestión da mobilidade de xeito ben diferente. Así, nos Estados Unidos o estudo da mobilidade estivo supeditado á análise da oferta. Basicamente realizáronse modelizacións de fluxos e estudos de dimensionamento de grandes infraestruturas de transporte (nomeadamente autoestradas). Predominou unha achega econométrica e un emprego xeral dos métodos cuantitativos. 
Pola súa banda, en Europa desenvolvéronse aproximacións dentro da Xeografía Rexional, nun primeiro momento, e de tipo máis social e humanista máis tarde. Estas segundas aproximacións centráronse na dimensión social e na importancia das variábeis persoais no estudo da mobilidade. Maioritariamente, empregáronse técnicas de análise cualitativas, que permitiron profundar no papel da dimensión humana da mobilidade.

A finais dos anos 1990 (HOYLE e KNOWLES, 1998), emerxeu unha "Moderna Xeografía do Transporte", como resultado da integración destas dúas grandes tendencias no estudo do transporte. O feito máis simbólico e significativo foi a organización por parte do Grupo de Xeografía de Transporte da AAG de dúas sesións tituladas Geography of Mobility, no seu congreso anual de Los Ángeles, celebrado no ano 2002 (PAZOS, 2003). O estudo xeográfico da mobilidade quedaba así encadrado dentro da Xeografía do Transporte, de xeito que en moitas das achegas xeográficas sobre o tema existe unha identificación de facto entre os termos transporte e mobilidade, aínda cando non son exactamente o mesmo (PAZOS, 2012).

Neste senso, e dentro da bibliografía en castelán, destaca o libro "Turismo y transporte", de BLASCO (2001), que aborda o estudo dos modos de transporte e o turismo por separado. Porén despois de ambas as dúas análises individuais analiza tamén a utilización con finalidade turística dos diferentes modos de transporte.

Pola súa banda, na bibliografía en portugués salienta PALHARES (2002), quen alén de realizar un estudo das relacións entre transporte e turismo, aborda casos nos que o transporte constitúe unha parte fundamental de determinados produtos turísticos. Na súa análise dos camiños de ferro, afirma que

o transporte ferroviário exclusivamente destinado ao segmento turístico tem despertado cada vez mais interesse, principalmente aqueles voltados às viagens cênicas, como os trens panorâmicos, e a viagens nostálgicas efetuadas em antigas locomotivas a vapor, tais como as marias-fumaça (PALHARES, 2002: 285).
Con posterioridade, PAGE (2005), volvendo sobre traballos seus publicados en 1994, retomará a cuestión da relación entre transporte e turismo. Este autor denomina "transporte para o turismo", ao mecanismo utilitario que permite transportar os turistas. Corresponde coa viaxe entendida na actualidade tal como a definíamos ao principio: desprazarse entre dous puntos no menor tempo e co menor custo posíbel. No "transporte para o turismo" a paisaxe non se percibe (viaxes en avión) ou percíbese fugazmente debido á velocidade de desprazamento e/ ou ás características das infraestruturas.

Por outra banda, dáse "transporte como turismo" onde o transporte permite un desprazamento e, asemade, é a base dunha experiencia turística. O custo de tempo e a velocidade xa non son relevantes. Antes ben, o turista busca precisamente a mobilidade lenta para poder gozar da paisaxe. E ademais está disposto a pagar bastante máis do que pagaría por desprazarse convencionalmente entre os dous puntos do percorrido.

Dentro da bibliografía non latina, GUNN e VAR salientan a importancia do transporte como elemento de éxito para todos os destinos turísticos (GUNN e VAR, 2002: 52). Porén tamén sinalan determinados elementos de destinos (estradas con alto valor paisaxístico, trens turísticos, etc.) que presentan un importante valor turístico por si mesmos. Neste senso, resulta de interese a súa conceptualización sobre as estradas con alto valor paisaxístico (scenic highways):

A pesar de que podería darse un consenso sobre que é unha estrada escénica, definila co obxectivo de planificala, construila ou protexela constitúe un asunto moi complexo. Polo xeral acéptase o principio de que a devandita estrada engloba tanto a paisaxe que se ve como propiamente a infraestrutura viaria. Porén, non hai unha definición aceptada de estándares de deseño [...]. Cada caso precisará a súa propia definición e estándares. (GUNN e VAR, 2002: 256).

Á marxe do marco de estudo da Xeografía do Transporte, salientan os estudos sobre as estradas con valor paisaxístico realizados desde 
a Arquitectura ou a Enxeñaría. Entre eles cabe destacar os traballos de AGUILÓ (1984, 2009, 2010), ESPAÑOL (2007, 2008) ou OTERO e outros (2006). Fóra de España, debemos sinalar os traballos de axencias e departamentos gubernamentais especializados en paisaxe e transporte de países como Francia, Reino Unido, Estados Unidos ou Canadá. En todos estes casos analízase a importancia das estradas na posta en valor das paisaxes, e ofrécense tamén recomendacións para planificar, construír, explotar e conservar as devanditas estradas (AIZPURÚA, 2009).

No presente traballo faremos unha análise da situación das estradas escénicas e o seu papel na apreciación e o gozo da paisaxe desde o movemento. Aínda que xerou menos debate e literatura académica, tamén abordaremos o caso dos camiños de ferro escénicos, outro dos grandes xeitos de gozar das paisaxes desde o movemento.

\section{As estradas e a paisaxe}

As estradas son importantes eixos a partir dos cales o desprazamento permite coñecer e gozar da beleza das paisaxes. Como indica ESPAÑOL (2007), as estradas proporcionan un acceso de calidade, rápido e seguro á paisaxe.

Cómpre sinalar o dobre papel da estrada, como elemento constitutivo da paisaxe e como elemento que permite o achegamento á paisaxe. Sobre o primeiro destacan os traballos de enxeñeiros como AGUILÓ (1984, 2010) ou NÁRDIZ (2006), e arquitectos como TARRAGÓ (2008), que analizaron as obras públicas e a súa integración na paisaxe; en moitos casos esta última vese realzada debido a unha coidadosa planificación da inserción da infraestrutura en cuestión, como é o caso de certos viadutos ou estradas de montaña.

Sobre o segundo papel das estradas, son maiores as achegas académicas. Así, algúns autores atrévense a indicar que as estradas non só son vías de transporte, senón que "constitúen un medio a través do cal o individuo entra en contacto coa paisaxe" (OTERO et al., 2006: 40). Nesta liña tamén está NOGUÉ (2005) cando afirma que "as estradas non son unicamente vías de transporte, senón que se converteron na pla- taforma fundamental da percepción e gozo da paisaxe para a inmensa maioría dos cidadáns". Pola súa banda, ESPAÑOL (2007: 32), nun traballo sobre os valores paisaxísticos da rede de estradas locais, indica que para moitas persoas "o primeiro contacto coa paisaxe tense dende a xanela do coche".

A referencia ás estradas locais non é casual, tendo en conta precisamente que estamos a falar de mobilidade lenta. Como argumentabamos ao principio, as modernas vías rápidas e autoestradas son incompatíbeis co gozo da paisaxe, de aí que sexan as estradas locais, máis estreitas, con limitacións de velocidade e con menor intrusión na paisaxe, as que permitan ao automobilista "internarse" dentro dela e poder así vivila máis de preto. De todos os xeitos, é certo que a contemplación da paisaxe desde as vías de alta capacidade pode verse facilitada se existe unha sinalización adecuada que amosa e explica graficamente como é a paisaxe. Este é o caso, moi en particular, de Francia, onde é habitual atopar nas autoestradas paneis cunha representación paisaxística moi ben conseguida que sintetiza o carácter da paisaxe que se cruza.

Partindo da idea de NOGUÉ anteriormente enunciada, podemos afirmar que as estradas locais desempeñan un papel fundamental na "democratización" da paisaxe e na súa apertura ao conxunto da cidadanía, facilitando o acceso a lugares remotos ou de singulares valores paisaxísticos, entre os cales ocupan un lugar preferente os espazos de montaña ou de fortes desniveis topográficos (Fig. 1).

Como indica ESPAÑOL (2007: 34), as estradas locais posúen varias características, entre as que destacan "dar acceso ás paisaxes, desenvolver os valores paisaxísticos do itinerario e ser xanelas abertas onde se mira a paisaxe".

É evidente que moitas estradas posúen elevados valores paisaxísticos e escénicos per se. Moitas estradas que discorren por espazos litorais acantilados, áreas de montaña ou espazos en xeral con atractivo paisaxístico son á vez itinerarios recomendados para a realización do turismo escénico. Deste feito faise eco a guía de estradas Michelin, en cuxa cartografía aparecen marcadas de cor verde todas aquelas estradas que teñen valor escénico. A presenza de árbores plantadas 


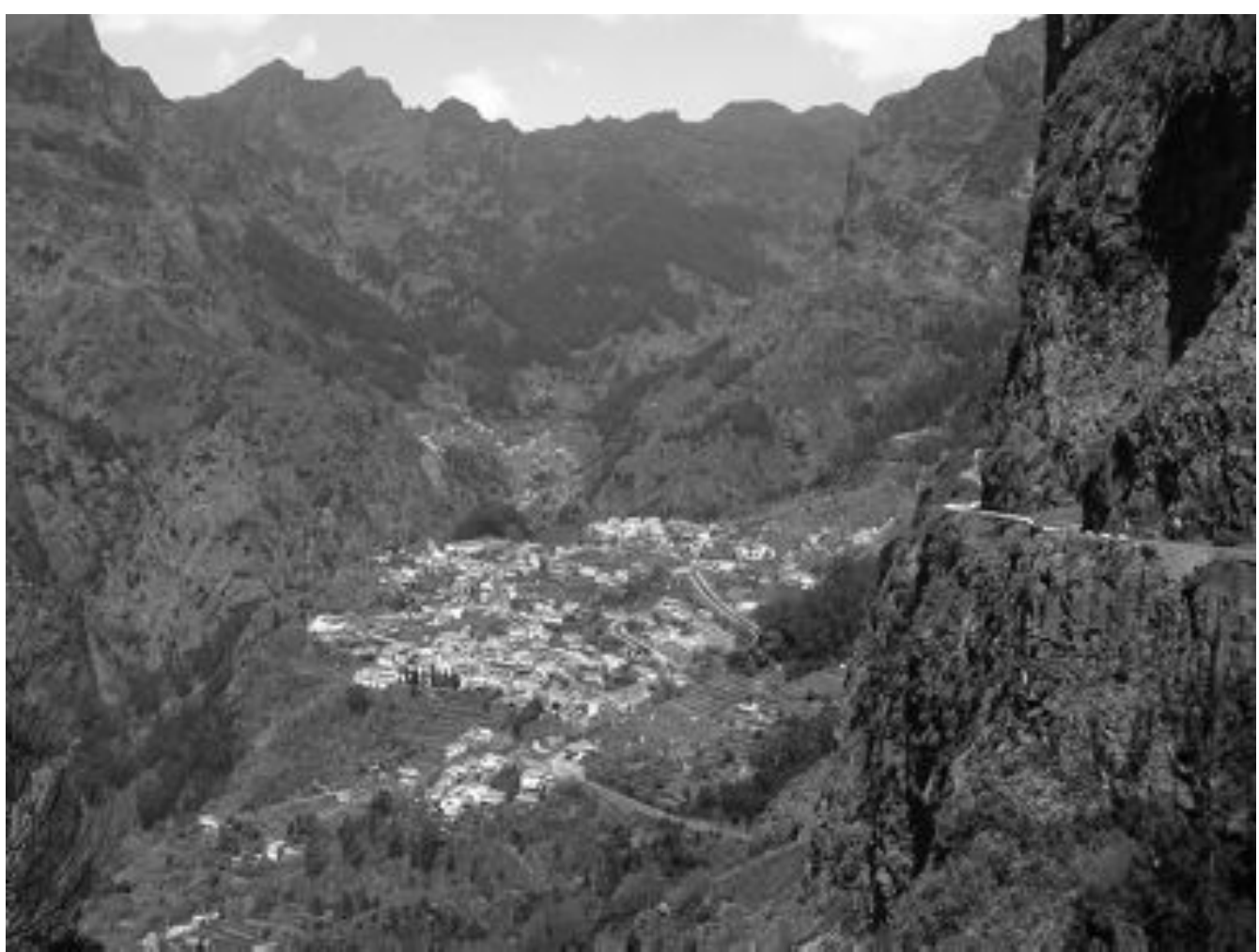

Fig. 1: Estrada de alto valor escénico na illa de Madeira. Acceso ao Curral das Freiras. Fotografía de Miguel Pazos Otón.

en ringleira cada varios metros nas beiras da estrada pode contribuír notabelmente a dignificar a estrada e a paisaxe que se cruza (TARRAGÓ, 2008); asemade, no verán permite a sombra, o que resgarda dos raios directos do sol.

Na nosa achega buscamos aproximarnos tamén ao papel que desempeña a planificación e a política de posta en valor das paisaxes en relación coas estradas. Parécenos interesante, xa que logo, centrarnos en casos onde as estradas escénicas son o resultado dun proceso de ordenación e planificación do territorio, na busca consciente de realzar e incrementar o valor paisaxístico do itinerario polo que discorren.

Se ben nos últimos anos avanzouse moito na incorporación de estándares de integración paisaxística na construción de estradas, e mesmo existe unha preocupación xeneralizada polo impacto estético das implantacións viarias, parécenos interesante poñer sobre a mesa certos casos de éxito onde se teñen desenvolvido ac- cións complexas e coherentes de posta en valor turística de estradas con forte valor paisaxístico. Analizaremos, polo tanto, senllos casos de estudo en Francia e Estados Unidos.

\subsection{Actuacións sobre as estradas e a pai- saxe en Francia}

En Francia desenvólvese unha importante tradición normativa que ten en conta a paisaxe como obxecto de protección, por parte dos poderes públicos. Pártese dun punto de vista que considera que a paisaxe é unha elección da sociedade (unha construción social por acción dos diferentes axentes), que combina o medio natural coas actuacións humanas subseguintes.

A Lei de Protección da Natureza de 1976 xa decreta a obriga de realizar un estudo de impacto ambiental con carácter previo aos proxectos de estradas. En 1993, a Lei de Protección e Posta en Valor das Paisaxes non limita só o concepto de paisaxe a aqueles con carácter excepcional, 
senón que toma en consideración o conxunto das paisaxes para definir as políticas de ordenación do territorio. Búscase, ante todo, conseguir paisaxes de calidade. A Lei de 1995 sobre o Reforzo da Protección da Natureza declara a paisaxe como patrimonio común, e anima á participación cidadá na conservación e mantemento da paisaxe. En efecto, anímase ás comunidades locais a elaborar proxectos de xestión para as paisaxes. A Convención Europea da Paisaxe, no ano 2000, faise eco da necesidade de valorizar a paisaxe en toda Europa e harmonizar as evolucións inducidas polas transformacións económicas e sociais.

Neste marco, dende comezos da década dos 1980 en Francia produciuse un incremento da preocupación pola paisaxe, avanzando notabelmente cara á súa comprensión e protección. Nos proxectos novos, normalmente cóntase con equipos de traballo pluridisciplinarios formados por persoas expertas en arquitectura, paisaxismo, arquitectura, xeografía, enxeñaría e outros profesionais, que estudan coidadosamente o impacto estético e paisaxístico das novas infraestruturas en planta, perfil e ao longo da traza da nova vía de comunicación (MINISTÉRE DE L'ÉQUIPEMENT, DES TRANSPORTS, DU LOGEMENT, DU TURISME ET DE LA MER, 2003).

Por outra banda, o Estado francés entende que é preciso implicar toda a cidadanía na protección, xestión, conservación e mantemento das paisaxes. Por iso desenvolveu un novo programa onde implica os poderes públicos e privados locais e rexionais na protección das mesmas. Ademais da motivación estética (que é fundamental), pártese da base de que unha paisaxe de calidade é fundamental para atraer un turismo de calidade, e polo tanto axudar ao desenvolvemento económico.

Neste senso, cabe sinalar a acción 1\% paysage et développement, que foi aplicada con carácter piloto en varias estradas do Macizo Central francés, coa fin de asegurar a xestión patrimonial das paisaxes e participar no desenvolvemento económico, evitando o deterioro da paisaxe. Tamén foi un obxectivo fundamental favorecer a promoción turística das comarcas atravesadas, incitando o viaxeiro a deixar as autoestradas e inducilo a transitar polas estradas, para así po- der apreciar mellor as paisaxes (MINISTÈRE DE L'AGRICULTURE, 2005).

O mecanismo consiste en que o Estado reserva o $1 \%$ do orzamento dedicado a unha estrada concreta para realizar unha análise territorial e paisaxística. Este estudo é fundamental para posteriormente poñer en marcha medidas de valorización e desenvolvemento, contando coa participación económica de colectividades territoriais, asociacións e diferentes axentes locais.

Primeiramente realízase un libro branco sobre cada itinerario, que fixa os grandes obxectivos de ordenación do territorio en relación co eixo da estrada. Posteriormente, os mapas do itinerario especifican as posibilidades de mobilización dos actores locais, que toman forma nunha serie de accións centradas na área de influencia da autoestrada.

Así, lánzase un programa de accións elixíbeis que son subvencionadas polo Estado, sempre e cando contribúan ao reforzamento da calidade estética e a protección da paisaxe. As accións susceptíbeis de seren financiadas son actuacións sobre espazos naturais, urbanos, paisaxes ou monumentos; actuacións sobre o desenvolvemento turístico; actuacións sobre edificios públicos ou privados; actuacións sobre liñas aéreas eléctricas e telefónicas, e actuacións sobre a calidade paisaxística dos terreos situados en torno ao eixo da estrada. Con este esquema de participación cidadá na xestión da paisaxe, un ben de interese xeral, conséguese non só unha protección efectiva da paisaxe, senón avanzar na gobernanza efectiva do territorio.

Dentro do mesmo programa destacan, ademais, outras dúas accións: as villages-étape e os itinéraires de découverte. Os dous parten da idea xa exposta de que a velocidade é dificilmente conciliábel co gozo da paisaxe. É preciso, polo tanto, estimular o automobilista que transita por unha autoestrada para que momentaneamente a abandone e goce de atractivos paisaxísticos, que deben ser por este motivo postos en valor convenientemente.

As villages-étape xorden como unha alternativa ás áreas de servizo das autoestradas e xeran un proceso de desenvolvemento local e de reposicionamento económico. Deben estar situadas a 
menos de 8 quilómetros dunha saída de autoestrada, pero ao mesmo tempo deben localizarse a máis de 20 quilómetros da área de servizo que conte con hotel e/ou restaurante máis próxima, coa fin de evitar a competencia.

As villages-étape deben ofrecer un sinal con información de calidade na entrada. O sinal debe informar sobre as infraestruturas con que conta (hoteis, restaurantes, aparcadoiros, etc), así como sobre os recursos paisaxísticos e culturais que ofrece ao viaxeiro, e que xustifican o desvío momentáneo da autoestrada.

Os itinéraires de découverte, pola súa banda, animan tamén o automobilista a deixar momentaneamente a autoestrada. A motivación é xerar o gozo da paisaxe grazas á circulación a menor velocidade por unha estrada convencional, ao longo dun itinerario alternativo ao percorrido previsto. Así, os itinéraires de découverte ofrecen unha ruta paralela dunha duración variábel entre media hora e unha hora. Os itinerarios está convenientemente sinalados na autoestrada e permiten descubrir as paisaxes locais menos coñecidas; logo facilitan o retorno á autoestrada unha ou dúas saídas despois da que se empregou para abandonala.

\subsection{As scenic highways californianas}

O outro grande conxunto de experiencias que pretendemos revisar puxéronse en marcha nos Estados Unidos, e en concreto en California, baixo a denominación de scenic highways. A súa orixe débese ao interese do Estado de California na preservación dos valores paisaxísticos ao longo das autoestradas, a través da creación do Master Plan of Scenic Highways. Naceron durante os 1960 e 1970 como un conxunto de itinerarios dunhas determinadas características. Sometidas a un réxime de protección específico por medio de instrumentos legais, estas estradas constituíronse como un conxunto de itinerarios preservados de actuacións urbanísticas e impactos negativos, coa fin de reforzar a apreciación dunhas paisaxes de referencia singulares (GOVERNMENT OF CALIFORNIA, 1974).

Deste xeito, cando unha vía de comunicación é clasificada como unha autoestrada paisaxística (scenic highway), o corredor paisaxístico (scenic corridor) é protexido de varios xeitos para asegurar que a visión dende a estrada é viábel, e pode manterse e mesmo mellorarse. Para lograr isto, regúlanse os usos do solo, os estándares de construción, as actuacións con implicacións medioambientais e protéxense as bacías visuais dende as autoestradas (CITY OF CAMARILLO GENERAL PLAN, 1984).

O obxectivo é a creación dun sistema coordenado de rutas paisaxísticas (scenic routes), que formarán unha auténtica rede de espazos abertos de interese paisaxístico. Pártese da idea de que os corredores seleccionados deben percorrer itinerarios cun valor notábel e consistente dende o punto de vista paisaxístico, estético e/ ou histórico, se ben se privilexian fundamentalmente itinerarios que decorran por espazos con predominio das paisaxes naturais.

O desenvolvemento destas vías de comunicación inclúe asemade unha serie de estándares de construcións para aqueles edificios de nova planta. As normativas regulan o encaixe da nova vía ás características topográficas do terreo, a eliminación de noiros, a provisión de vexetación onde sexa preciso para evitar o afloramento de cortes, o corte e a limpeza de vexetación para conseguir bacías visuais determinadas, o control da erosión nas vertentes e a provisión de miradoiros e aparcadoiros en espazos onde as vistas sexan especialmente atractivas.

As distintas disposicións que regulamentan a xestión das vías de interese paisaxístico ofrecen en realidade un complexo abano de normas de intervención sobre o territorio, coa fin de preservar as características paisaxísticas singulares do scenic corridor. Así, existen disposicións que regulan o soterramento de cableado aéreo, a plantación e mantemento de árbores, o sementado de vexetación nos contornos da vía, a instalación de pantallas illantes sonoras, e outras medidas.

O deseño dun scenic corridor leva aparellada a obrigatoriedade de realizar un inventario territorial de elementos e recursos, no que a Xeografía ten un papel relevante. Despois realízanse plans e programas para identificar as accións que deben crear, realzar ou preservar a calidade paisaxística do corredor, que se van desenvolvendo conforme ás pautas referidas. 


\section{Os camiños de ferro escénicos}

As vías férreas foron e son excelentes eixos vertebradores de rutas e incursións a través das paisaxes. O ferrocarril foi o primeiro modo de transporte que permitiu desprazamentos frecuentes entre distancias medias e longas para o conxunto da sociedade, de xeito que fixo posíbel para a toda a poboación descubrir paisaxes inéditas, doadamente apreciábeis dende a xanela dos vellos vagóns. No imaxinario colectivo, a vía férrea e o ferrocarril en xeral teñen sido asociados sempre coa observación e o gozo da paisaxe. Isto é así debido ás propias características do trazado das vías férreas, polo xeral máis integradas na paisaxe e cun menor impacto no contorno.

$\mathrm{Na}$ actualidade existen moitas liñas de ferrocarril no mundo que teñen como un dos obxectivos principais o gozo estético das paisaxes. En moitos casos estes trens son recreacións ou herdeiros de antigos trens históricos (en moitos casos do século XIX), nos que se combina o gusto pola nostalxia e saudade do pasado, a curiosidade e o gusto pola apreciación das paisaxes percorridas a velocidade lenta.

A explotación comercial destes trens pode producirse basicamente de dous xeitos. En primeiro lugar están os trens só para turistas. Con frecuencia conforman produtos turísticos moi coherentes nos que o material rodante é de época (locomotora de vapor, coches antigos, mobiliario, etc), e soen ir asociados á exclusividade e ao luxo, sobre todo se os percorridos se efectúan ao longo de varios días. O máis habitual é que estes produtos de varios días se presenten ao público como un paquete "todo incluído" onde destaca a calidade do servizo e a realización de excursións complementarias en torno ás principais paradas intermedias.

Como exemplo clásico desde ferrocarril temos o Blue Train da África do Sur, que discorre entre Pretoria e Cidade do Cabo. En España podemos mencionar o caso do Transcantábrico, un ferrocarril de vía estreita que percorre o norte peninsular, enlazando entre si as comunidades autónomas da España Verde. O pintoresco trazado da vía férrea no norte de España, adaptándose a unha orografía difícil, e discorrendo á beira dunha costa con frecuencia acantilada fai que a compoñente paisaxística teña unha presenza importante.

En canto á oferta de trens turísticos de menos dun día, é moito máis ampla. Na súa grande maioría son tamén recreacións de trens históricos ou de época, e en moitos casos foron construídos xa dende un primeiro momento cunha finalidade escénica. Entre eles podemos mencionar o caso do camiño de ferro de Snowdonia, en Gales. Trátase dun ferrocarril de montaña que acada o cumio Snowdon, de máis de 1.000 metros de altitude, dentro do Snowdonia National Park. O principal reclamo para a utilización deste ferrocarril é a paisaxe e, sobre todo, as fantásticas vistas dende o cumio, que segundo a publicidade oficial do parque, poden chegar até 160 kilómetros, abranguendo Irlanda.

Un caso interesante na mesma dirección é o do ferrocarril de vapor que realiza o percorrido entre York e a localidade costeira de Scarborough, no Reino Unido. Utiliza unha locomotora de comezos de século, a que levaba o tren Flying Scotsman, que realizaba o servizo entre Londres e Glasgow en pouco máis de 4 horas. Tamén os vagóns son de época, o que o converte nun apetecíbel e moi rendíbel produto turístico (Fig. 2).

Outro exemplo clásico de camiño de ferro turístico, neste caso de alta montaña, é o ferrocarril suízo que enlaza Grindelwald co Jungfraujoch, aos pés do monte Eiger. Situado en plenos Alpes berneses, o ferrocarril permite apreciar en toda a súa grandiosidade o verde val de Grindelwald, a cara norte do Eiger e outros picos e, dende logo, o glaciar do Jungfrau, desde un observatorio-cafetería situado ao final da liña. Este achegamento do corazón da natureza alpina ao conxunto da cidadanía (e non só aos alpinistas) amosa a receptividade da cidadanía desde comezos do século $X X$ ante a grandiosidade das paisaxes.

Noutros casos, o ferrocarril, cunha importante compoñente escénica, forma parte dun produto turístico tematizado coherente. Un bo exemplo é o Durango \& Silverton Narrow Gauge Railway, recreación dun antigo trazado dende Durango até as minas de Silverton, en Colorado (Estados Unidos). Neste caso, ofértase o percorrido en tren até a mina, unha visita ao interior 


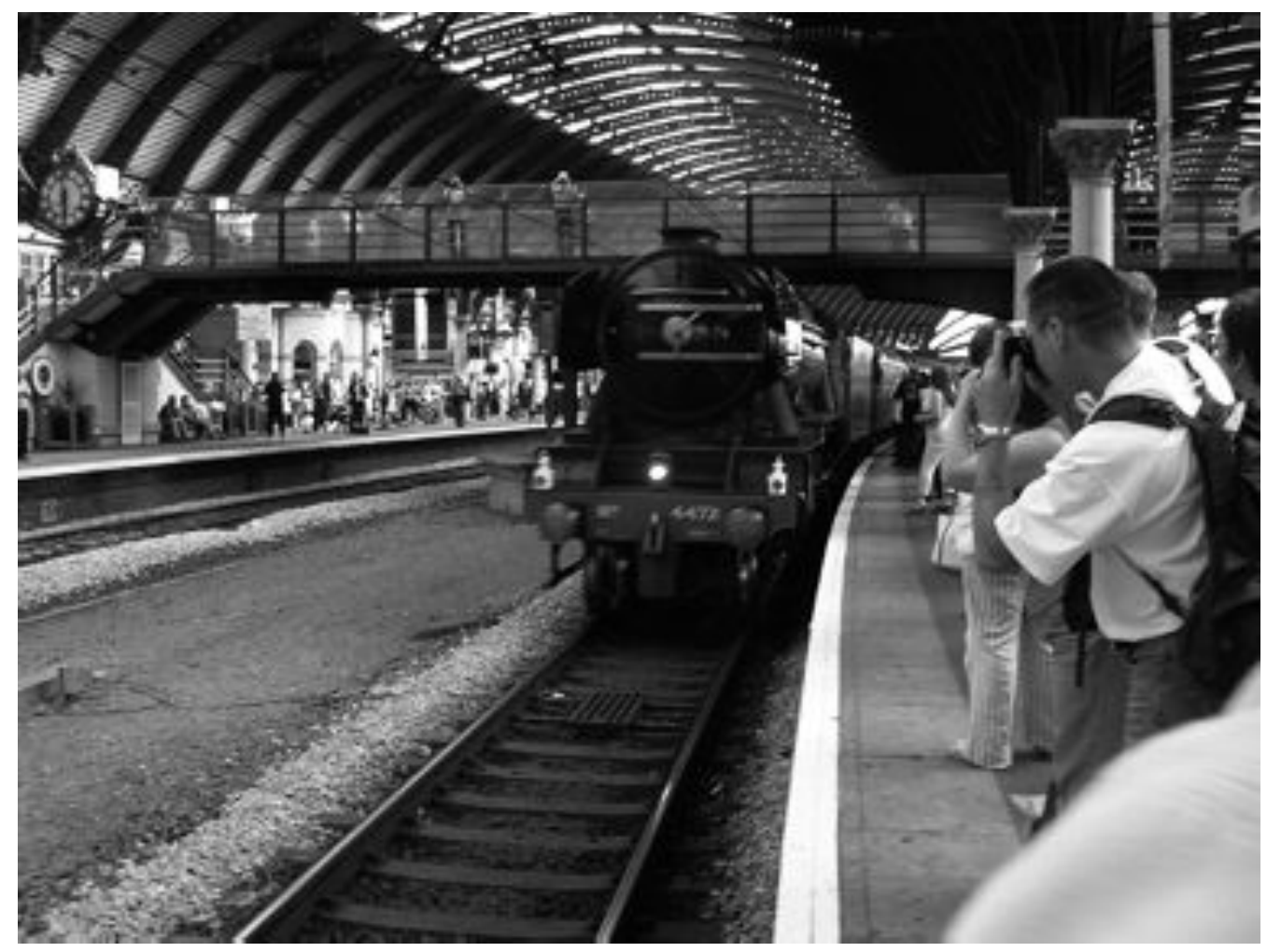

Fig. 2: A locomotora de vapor Flying Scotsman, que cobre o traxecto turístico York-Scarborough, entrando na estación de York. Fotografía de Miguel Pazos Otón.

da mina de prata nunha vagoneta eléctrica especial para turistas e o regreso a Durango. Está concibido como un produto full-day excursion, cunha duración total de 9 horas.

En segundo lugar, canto aos trens non exclusivamente turísticos, trátase de servizos mixtos, onde se ofertan diferentes tipos de billetes, para usuarios convencionais e para turistas. Os trens son herdeiros de ferrocarrís históricos (como é o caso do Transcanadiano), pero non se recrea o material rodante nin o ambiente de época. Porén nos lugares destinados a turistas contan cunha serie de equipamentos especialmente dirixidos a eles.

No Transcanadiano, que percorre o país de leste a oeste, vai equipado con observatory decks, unhas cúpulas transparentes no teito dos vagóns, que permiten ao turista unha observación da paisaxe panorámica, en 360 graos. En clase turista, os asentos son amplos e reclinábeis, e posúen repousapés. O servizo, semellante ao dun avión, proporciona mantas e almofadas para pasar a noite. En clase de luxo pódese gozar de maiores comodidades, convertendo ao hotel nun verdadeiro tren rodante. Unha situación semellante atopámola no Transiberiano, que circula entre Moscova e Vladivostok, atravesando Rusia, ou, en Australia, o Indian Pacific entre Perth e Sydney e mais The Ghan entre Adelaide e Darwin.

Evidentemente, existen trens que realizan servizos regulares convencionais que son utilizados para realizar turismo escénico, debido á singularidade dos seus trazados e á beleza paisaxística. Entre eles podemos destacar os trens da Provenza francesa, o tren no norte noruegués, o ferrocarril do norte de Inglaterra (nos Yorkshire Dales) ou, en Galicia, o ferrocarril que discorre polo canón do río Sil. 


\section{Conclusións}

A paisaxe é unha construción que a sociedade elabora, partindo de valores culturais, estéticos, sociais e ambientais. É produto da proxección sobre o espazo dun sistema de valores propio dun lugar e un tempo concretos, e pode lerse a través dun código de signos que a Xeografía interpreta como disciplina social e territorial.

A relación entre transporte, mobilidade e paisaxe é moi estreita. Da concepción utilitarista das infraestruturas de transporte como meros soportes da mobilidade pasouse a unha nova dimensión, onde a estrada ou a vía férrea considéranse como parte integrante da paisaxe, e constitúen excelentes medios para a aprehensión e o gozo espontáneo da paisaxe por parte das persoas que viaxan.

No momento actual, a variábel velocidade transforma os anteriores viaxeiros en persoas que se desprazan rapidamente, co propósito de chegar no menor tempo posíbel ao seu punto de destino. A velocidade e o "efecto túnel" que caracteriza as novas infraestruturas de transporte explican o deterioro do binomio infraestruturas liñais-paisaxe, moi visíbel sobre todo nas estradas.

As estradas, tradicionais "escolas" de percepción da paisaxe para a cidadanía, perderon en gran medida esta función complementaria á súa propia como soporte físico da mobilidade. Para paliar esta situación, preténdese recuperar a relación entre estrada e paisaxe, a partir da mobilidade lenta e da recuperación das estradas locais. Ante a mobilidade rápida das autoestra- das e vías semellantes, existe toda unha reivindicación das estradas locais como elementos que posibilitan coñecer a paisaxe co menor impacto posíbel. Cada vez están máis xeneralizadas as normas de integración paisaxística das estradas, que tentan minimizar o seu impacto na paisaxe.

Entre as novas medidas destaca a promoción da implicación dos axentes locais na conservación e mantemento de diferentes elementos que conforman a paisaxe nas marxes das estradas. En Francia estanse a desenvolver mecanismos de participación cidadá nesta liña. Tamén en Francia se levaron á práctica ideas como as villages-étape ou os itinéraires de découverte, que conseguen con éxito desviar os automobilistas cara ás estradas locais, onde poden apreciar mellor a paisaxe. Pola súa banda, en California vénse traballando nas estradas paisaxísticas (scenic highways), a través dunha serie de accións coherentes que se enmarcan nun plan integral de valorización da paisaxe partindo das vías de comunicación, en estreita relación coa ordenación do territorio.

Canto aos camiños de ferro, constitúen outro xeito moi interesante de achegarse ás paisaxes desde o movemento. Pola súa propia natureza, o tren préstase á conformación de atractivos produtos turísticos, que recrean camiños de ferro históricos ou de época. Poden constituír produtos moi complexos, pero neles o gozo da paisaxe sempre é un elemento central. O auxe da recuperación destes camiños de ferro, ao igual que no caso das estradas escénicas, está en relación coa demanda crecente por parte da sociedade de gozar das paisaxes, neste caso dende o movemento (lento). 


\section{Bibliografía}

AGUILÓ ALONSO, M. (1984): "Identificación de tramos de carretera con interés paisajístico". Revista de Obras Públicas, mayo 1984, pp. 329344.

AGUILÓ ALONSO, M. (2009): “El diseño de la carretera como acceso, paisaje y monumento". En: $2^{\circ}$ Congreso de Paisaje e Infraestructuras. Centro de Estudios, Paisaje y Territorio. Junta de Andalucía, pp. 17-34. Sevilla.

AGUILÓ ALONSO, M. (2010): "El paisaje de las obras públicas". Estudios Geográficos, Vol. LXXI, 269, pp. 601632.

AIZPURÚA GIRÁLDEZ, N. (2009): "Denominación: Carreteras Paisajísticas". En: $2^{\circ}$ Congreso de Paisaje e Infraestructuras. Centro de Estudios, Paisaje y Territorio. Junta de Andalucía, pp. 139-136. Sevilla.

ALLEN, J. e HAMNETT, C. (1995): "Annihilating space? The speed-up of communications" en Allen, J. y Hamnett, C. (1995) (Eds.): A shrinking world? Global Unevenness and Inequality, Oxford: Oxford University Press.

BAUMAN, Z. (2003): Modernidad líquida. Fondo de Cultura Económica. Buenos Aires

BAILLY, A.S. (1979): La percepción del espacio urbano. Madrid: IEAL

BLASCO, A. (2001): Turismo y transporte. Madrid: Síntesis.

CITY OF CAMARILLO GENERAL PLAN (1984): Scenic Highways. Camarillo (California).

CONSEIL REGIONAL ILE-DE-FRANCE (2000): Geometrie de la Route et Relation au site. Les Routes Vertes. Volume 3, September 2000. París.

COUNTRYSIDE COMMISSION (1995) "Roads in the Countryside", Advisory Booklet. Countryside Commission, London.

CRESSWELL, T. (2006): On the move: mobility in the modern Western World. New York: Taylor \& Francis.

DEPARTMENT OF TRANSPORTATION (1980): "Environmental design guidelines for roads", Test Research Consulting Transportation and Environmental Systems, Cagliari, 1980, Alberta, Canada.

ESPAÑOL ECHÁNIZ, I. (2007): "LoS valores paisajísticos de la Red Local de Carreteras". Revista de Obras Públicas, $n^{\circ} 3.487, \mathrm{pp}-31-40$.

ESPAÑOL ECHÁNIZ (coord.). (2008): La carretera en el paisaje: criterios para su planificación, trazado y proyecto. Sevilla: Junta de Andalucía.

GOVERNMENT OF CALIFORNIA (1974): State scenic highway system: progress report including recommendations of the Advisory Committee on a Master Plan for Scenic Highways. Sacramento.

GUNN, C.A.; VAR, T. (2002): Tourism Planning: Basics, Concepts, Cases. $4^{\text {a }}$ ed. New York/London: Routledge.

GUTIÉRREZ PUEBLA， J. (1988): "Redes, espacio y tiempo". Anales de Geografía de la Universidad Complutense de Madrid, n 18, pp. 65-86.

HANDY, S. (1997): Measuring accesibility: an exploration of issues and alternatives. En: Environment and planning $A, 29,1175-1194$.

LEFEBVRE, H. (1991): The Production of Space. Oxford: Blackwell.

MINISTÉRE DE L'ÉQUIPEMENT, DES TRANSPORTS, DU LOGEMENT, DU TURISME ET DE LA MER (2003): Le Paysage et la Route. París.

NÁRDIZ ORTIZ, C. (2006): "Infraestructuras y creación de paisajes". Libro de actas del Primer Congreso Paisaje e Infraestructuras. Centro de Estudios, Paisaje y Territorio. Junta de Andalucía, pp. 105-117. Sevilla.

NOGUÉ, J. (2005): "Carreteras y paisajes". En La Vanguardia, Barcelona.

OTERO, I.; CAÑAS, I.; ESPARCIA, P.; NAVARRA, M.; MARTÍN, M.C.; ORTEGA, E. (2006): "La carretera como elemento de valor paisajístico y medioambiental. Captación del valor del paisaje a través de la carretera". Informes de la Construcción, vol. 58, 504, pp. 39-54
PAGE, S.J. (2005): Transport and Tourism. Global Perspectives. Harlow: Pearson.

PALHARES, G.L. (2002): Transportes turísticos. São Paulo: Aleph.

PAZOS OTÓN, 2003: Movilidad de la población en la Galicia Occidental: el Eje Urbano Atlántico gallego. Tesis doctorales en CD-rom. Santiago de Compostela: Universidade de Santiago de Compostela.

PAZOS OTÓN, M. (2005): Pontevedra Litoral: hacia una ciudad continua. Pontevedra: Deputación Provincial de Pontevedra.

PAZOS OTÓN, M. (2012): "Transportes y movilidad en la sociedad de la información". En: LOIS, R.C.; ARMAS, F.; MACÍA, X.C., CABALAR, M. e CARDOSO DA SILVA, L. (eds): Planificación y estrategias territoriales en la sociedad actual. Santiago de Compostela: Servizo de Publicacións da Universidade de Santiago de Compostela (EN PRENSA).

MINISTÈRE DE L'AGRICULTURE (2005): Circulaire du 31 Mars 2005 relative à la politique $d u$ " $1 \%$ paysage et développement" sur le réseau routier national. París.

SHELLER, M.; URRY, J. (2006): "The new mobilities paradigm". Environment and Planning A, volume 38, pp. 207-226

TARRAGÓ, S. (2008): Paisatges construïts. Patrimoni i cultura a l'obra pública de Catalunya. Barcelona: Publicacions de l'Abadia de Montserrat.

THRIFT, N. (1996): Spatial formations. Londres: SAGE.

URRY, J. (2007): Mobilities. Cambridge: Polity Press.

VIRILIO, P. (2006): Velocidad y politica. Buenos Aires: Editorial La Marca.

ZOIDO NARANJO, F.: "Paisaje e infraestructuras. Interacción, sinergias y prioridades de actuación". En: Libro de Actas del Primer Congreso Paisaje e Infraestructuras. Centro de Estudios, Paisaje y Territorio. Junta de Andalucía, pp. 35-51. Sevilla. 